\title{
$p$ value variability and subgroup testing
}

\author{
Graham Horgan ${ }^{1}$ (D)
}

Received: 18 December 2020 / Accepted: 22 January 2021 / Published online: 13 February 2021

(c) The Author(s) 2021

\begin{abstract}
This article discusses the variability and randomness of $p$ values, the most widely used currency of evidence in nutritional and health studies. One implication of this, the importance of always testing interaction terms when subgroups are examined and presented separately is also discussed.
\end{abstract}

Keywords $p$ value $\cdot$ Interaction $\cdot$ Subgroup

\section{Introduction}

$p$ values are ubiquitous in nutritional research, as they are across nearly all the health and biological sciences. In any issue of this journal all or almost all of the research papers include $p$ values somewhere. With such an impressive breadth of usage, there comes the risk of abuse, and accordingly $p$ values have come in for criticism recently [1-5]. This criticism has been less heard in nutritional science, and it is not the aim of this article to initiate such an attack here. Many of the issues raised elsewhere are general enough to apply to research of the sort presented in this and related journals. The intention here is to draw attention to the variability of $p$ values, and the implications this has when repeating analyses in subgroups of a study.

\section{$p$ values}

We start by restating what a $p$ value is. We suppose that we are studying whether an effect (or a difference or an association, etc.) of interest exists. The $p$ value is the probability that, in the absence of such an effect, evidence in our data for this effect that is at least as strong as that we have observed could occur by chance. Thus it is a probability statement about the data, rather than a statement about the likelihood of the existence of the effect. If the latter is desired, then the Bayesian approach to data analysis [6] is needed.

Graham Horgan

g.horgan@abdn.ac.uk

1 Biomathematics and Statistics Scotland, Aberdeen, Scotland
It is also essential to remember that a $p$ value does not indicate the strength or importance of an effect, only the evidence we have that it is not zero. The word "significant" has come to be universally used to refer to a finding that $p<0.05$. When used by itself rather as the fuller expression "statistically significant", this very easily gives a potentially misleading impression that the finding is important and relevant. This may or may not be so: we need additionally to examine the effect size to consider what is termed its "clinical significance" [7, 8]. A finding is important when it has this as well as statistical significance.

What this article aims to draw to attention is that $p$ values are more random and unpredictable than might be realised. Those that are obtained at the end of a study might well have been different however much care and diligence there had been in carrying out the research and analysis.

To illustrate the variability of $p$ values, we consider a simple experiment: we compare two treatments in separate groups of human volunteers or animals, which have been randomly assigned to the two groups. Many experiments are more complex than this, but the same $p$ value variation would also be applicable there, or in observational studies. At the end of the experiment, we will compare the two groups with a $t$ test. Even in a simple two-group experiment, we will often carry out a more sophisticated analysis, such as including covariates or transforming non-Normally distributed variables. Again, the same $p$ value variability would occur in that case also.

We do not know before doing the experiment what the $p$ value will be. We can ask what the expected distribution is, i.e. what might we get? If there is no treatment effect, the distribution is uniform between 0 and 1 . So there is a 
1 in 10 chance that it will be less than 0.1 and a 1 in 20 chance that it will be less than 0.05 . That is the false-positive (type I error) risk that is unavoidable if conclusions are based on whether $p$ values are less than 0.05 or not.

Now suppose that there is in fact a treatment effect with a standardised effect size of $D=1.2$, i.e. the expected difference between the groups is 1.2 times the within group standard deviation. Let both groups have 12 volunteers or animals. With this sample size, a standard power calculation would return $80 \%$ [9], i.e. if $D=1.2$ is true then we have a four out of five chance that the $p$ value we will calculate at the end of the experiment will be $<0.05$, and the correct conclusion, that the treatment has some effect, will be made. There is then a one in five chance that $p>0.05$, leading to a false negative (type II error).

Figure 1 shows the expected distribution of $p$ values from this experiment. We can think of this as a histogram of the $p$ values that would occur across a large number of experiments in all of which $n=12$ per group and the power is $80 \%$. The shape of this distribution would change only slightly for other experiments with $80 \%$ power but different sample sizes, or for different designs or different analyses. As expected, there is $80 \%$ probability that $p<0.05$, However there is also an $8 \%$ probability that $p>0.2$. One in five experiments studying real treatment effects with $80 \%$ power for the primary outcome will wrongly conclude that the treatment has no effect, and it will not necessarily be the case for all of these that $p$ is close to $5 \%$.

\section{Subgroup comparisons}

One situation where we particularly need to be wary of the variability of $p$ values is when we compare them in different experiments, different outcomes or different subgroups of the same experiment. It is this latter situation we examine here. Suppose that our volunteers or animals are a 50:50 mix of male and female. We may then wonder whether the treatment effect differs between them, and carry out the $t$ test or other analysis separately for male and female subgroups.

The two sample sizes here will be half the total sample size and the original $80 \%$ power will be reduced to about $50 \%$ in each case. Although we are assuming here that the effect is in fact the same for both subgroups, it could readily occur that we find a significant difference in one subgroup but not in the other. Indeed there is a 50\% chance that this will occur, potentially leading to erroneous conclusions. This follows from the $50 \%$ power, so the four possibilities of significance for $\mathrm{F}$ only, $\mathrm{M}$ only, neither or both are equally likely.

Figure 2 shows the distribution of subgroup $p$ values for a situation like this, where there is a treatment effect of $D=0.74$, for both F and M subgroups, and 30 volunteers or animals in total per treatment group, again giving a power of $80 \%$. The distribution shown is for tests in subgroups of size $n=15$. It can occur quite readily that a clearly significant $p$ value is seen in one group (there is about a one in four chance that it will be $<0.01$ ) and a clearly non-significant $p$ value seen in the other (with also about a one in four chance that $p>0.2$ ). If this were translated into a conclusion that a
Fig. 1 Distribution of $p$ values for experiments with $80 \%$ power
Distribution of $p$-values

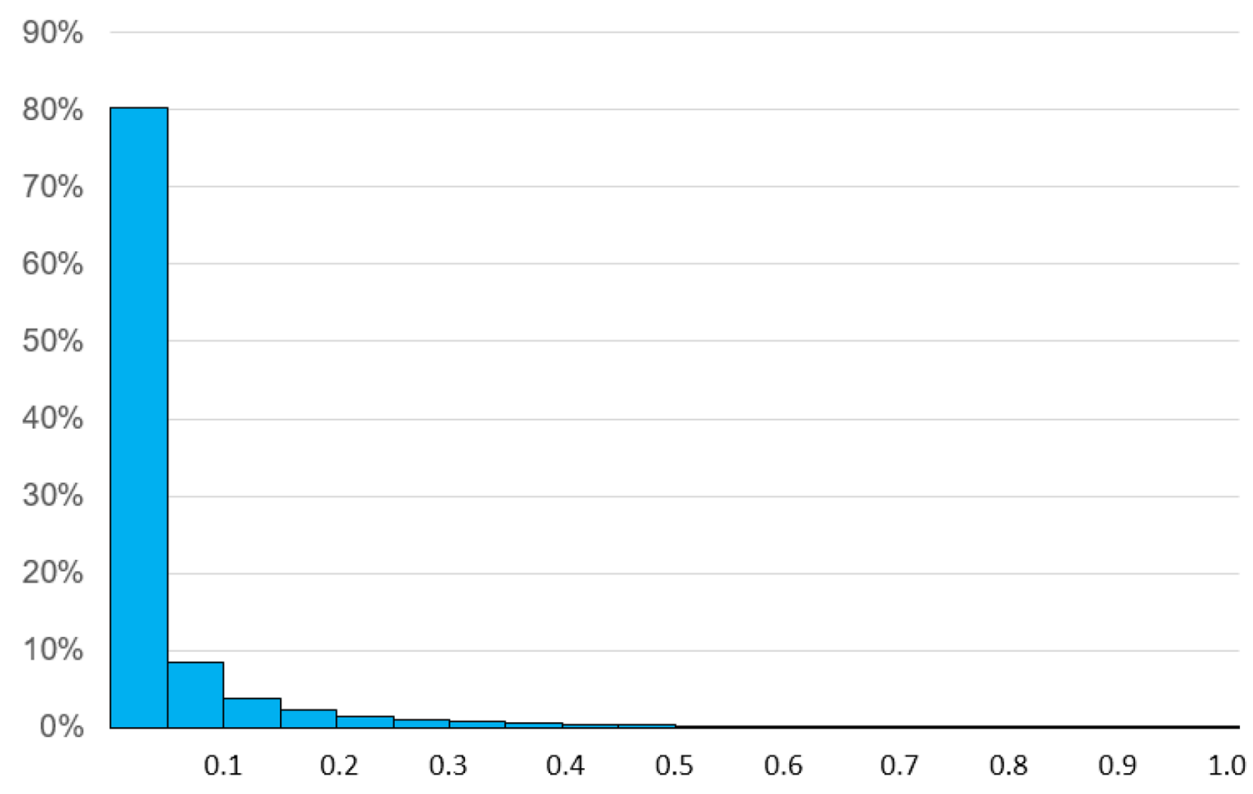


Fig. 2 Distribution of $p$ values in subgroup comparisons where power is $50 \%$

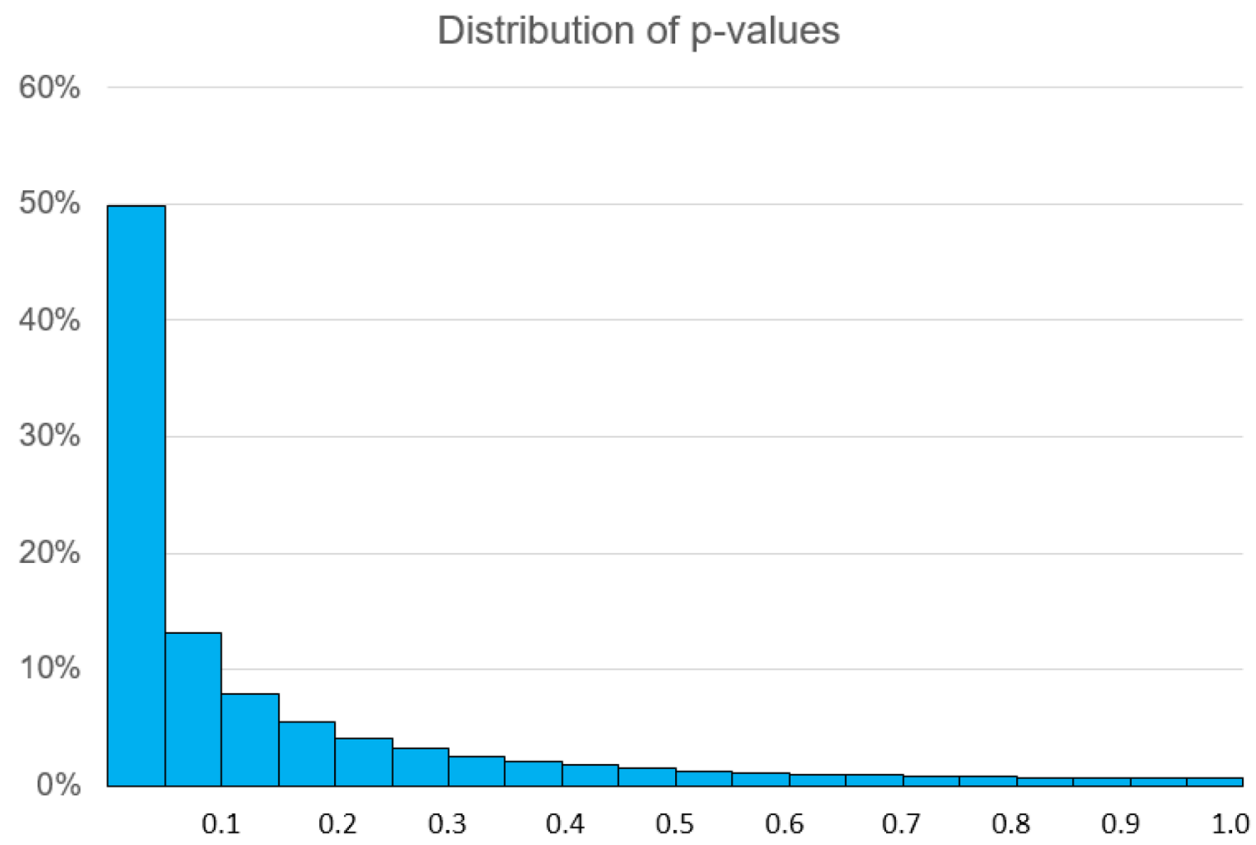

treatment effect exists in one subgroup but not in the other, it would be quite wrong.

To mitigate the risk of this misleading presentation of experimental results, two strategies can be used. The first is to note that it is usually inadvisable to examine subgroups when a test of the effect in the total sample shows no significant treatment effect. Unless planned in advance and with some scientific expectation or plausibility that effects might vary between subgroups, such testing gives an appearance of what is derided as data dredging [10] and so should be done in moderation and with caution [11-13]. It can be defended as data exploration, but if so the purpose should be hypothesis generation rather than testing, and should be used to suggest further research rather than draw conclusions. The second strategy is used when subgroups have been considered in advance. In this case, we should always include a test of an interaction between the treatment factor and the subgroup factor, and proceed to subgroup comparisons only if this interaction term is significant [14]. If it is not, then this interaction term test has provided no support to any idea that the subgroups differ in their treatment response. Whenever such differences are reported without an interaction term test being presented as well, they should be viewed with caution.

\section{Conclusion}

To conclude, this article is not calling for $p$ values to be abandoned, although such a view can be heard in scientific discussion. They remain a useful currency for discussion of the evidence that scientific studies are intended to produce. However, consideration of whether they lie on one side or other of the 0.05 (or any other) threshold can be given too much emphasis, and their intrinsic variability should be remembered when drawing conclusions and making decisions, with the estimated size of any effect also being given due attention.

Supplementary Information The online version contains supplementary material available at https://doi.org/10.1007/s00394-021-02498-z.

Acknowledgements This work was supported by funding from the Scottish Government Rural and Environment Science and Analytical Services Division (RESAS).

\section{Compliance with ethical standards}

Conflict of interest The author declares that they have no competing interest.

Open Access This article is licensed under a Creative Commons Attribution 4.0 International License, which permits use, sharing, adaptation, distribution and reproduction in any medium or format, as long as you give appropriate credit to the original author(s) and the source, provide a link to the Creative Commons licence, and indicate if changes were made. The images or other third party material in this article are included in the article's Creative Commons licence, unless indicated otherwise in a credit line to the material. If material is not included in the article's Creative Commons licence and your intended use is not permitted by statutory regulation or exceeds the permitted use, you will need to obtain permission directly from the copyright holder. To view a copy of this licence, visit http://creativecommons.org/licenses/by/4.0/. 


\section{References}

1. Hubbard R, Lindsay RM (2008) Why P values are not a useful measure of evidence in statistical significance testing. Theory Psychol 18(1):69-88. https://doi.org/10.1177/0959354307086923

2. Wasserstein RL, Lazar NA (2016) The ASA statement on p-values: context, process, and purpose. Am Stat 70(2):129-133. https ://doi.org/10.1080/00031305.2016.1154108

3. Munafo MR, Nosek BA, Bishop DVM, Button KS, Chambers CD, du Sert NP, Simonsohn U, Wagenmakers E-J, Ware JJ, Ioannidis PA (2017) A manifesto for reproducible science. Nat Hum Behav 1:0021. https://doi.org/10.1038/s41562-016-0021 (S2CID 6326747)

4. Halsey LG (2019) The reign of the p-value is over: what alternative analyses could we employ to fill the power vacuum? BiolLett 15:20190174. https://doi.org/10.1098/rsbl.2019.0174

5. Amrhein V, Greenland S, McShane B (2019) Retire statistical significance. Comment Nat 567:305-307. https://doi.org/10.1038/ d41586-019-00857-9

6. Berry DA, Stangl DK (eds) (2019) Bayesian biostatistics. CRC Press, New York (ISBN 978-0367401399)

7. Ranganathan P, Pramesh CS, Buyse M (2015) Common pitfalls in statistical analysis: Clinical versus statistical significance.
PerspectClin Res 6(3):169-170. https://doi.org/10.4103/22293485.159943

8. Aguinis H, Vassar M, Wayant C (2019) BMJ On reporting and interpreting statistical significance and $\mathrm{p}$ values in medical research. Evid-Based Med. https://doi.org/10.1136/bmjebm-2019111264

9. Cohen J (1988) Statistical power analysis for the behavioral sciences. Routledge, London (ISBN 978-1-134-74270-7)

10. Davey Smith G, Ebrahim S (2002) Data dredging, bias, or confounding. BMJ 325(7378):1437-1438. https://doi.org/10.1136/ bmj.325.7378.1437 (PMC 1124898. PMID 12493654)

11. Altman DG, Matthews JNS (1996) Interaction 1: heterogeneity of effects. BMJ 313:486. https://doi.org/10.1136/bmj.313.7055.486

12. Matthews JNS, Altman DG (1996) Interaction 3: how to examine heterogeneity. BMJ 1996(313):862. https://doi.org/10.1136/ bmj.313.7061.862

13. Matthews JNS, Altman DG (1996) Interaction 2: compare effect sizes not P values. BMJ 313:808. https://doi.org/10.1136/ bmj.313.7060.808

14. Wang R, Lagakos SW, Ware JH, Hunter DJ, Drazen JM (2007) Statistics in medicine-reporting of subgroup analyses in clinical trials. N Engl J Med 357(21):2189-2194. https://doi.org/10.1056/ NEJMsr077003 